\title{
Photoanode of Dye-Sensitized Solar Cells Based on a $\mathrm{ZnO} / \mathrm{TiO}_{2}$ Composite Film
}

\author{
Lu-Ting Yan, Fang-Lue Wu, Lan Peng, Li-Juan Zhang, Pu-Jun Li, \\ Sui-Yang Dou, and Tian-Xiang Li
}

School of Science, Beijing Jiaotong University, Beijing 100044, China

Correspondence should be addressed to Lu-Ting Yan, ltyan@bjtu.edu.cn

Received 6 April 2012; Accepted 12 July 2012

Academic Editor: G. N. Tiwari

Copyright (C) 2012 Lu-Ting Yan et al. This is an open access article distributed under the Creative Commons Attribution License, which permits unrestricted use, distribution, and reproduction in any medium, provided the original work is properly cited.

\begin{abstract}
A photoanode of dye-sensitized solar cells based on a $\mathrm{ZnO} / \mathrm{TiO}_{2}$ composite film was fabricated on a transparent conductive glass substrate using different techniques including electrophoretic deposition, screen printing, and colloidal spray coating. The ZnOs used in the composite film were $\mathrm{ZnO}$ tetrapods prepared via thermal evaporation and $\mathrm{ZnO}$ nanorods obtained via hydrothermal growth. The structural and morphological characterizations of the thin composite films were carried out using scanning electron microscope (SEM). The best power conversion was $1.87 \%$, which corresponds to the laminated $\mathrm{TiO}_{2} / \mathrm{ZnO} / \mathrm{TiO}_{2}$ structure prepared via screen printing.
\end{abstract}

\section{Introduction}

Dye-sensitized solar cells (DSSCs) have attracted increasing attention due to their high efficiency for energy conversion and low production cost compared with silicon solar cells [1, 2]. Photoanodes are important components of DSSC because of their functions in supporting dye molecules and transferring electrons. A high electron transport rate is required to reduce electron-hole recombination rate and enhance conversion efficiency. $\mathrm{ZnO}$ is one of the semiconductor materials containing abundant nanostructure morphologies and having high electron mobility (about $10^{-1}-10^{-3} \mathrm{~cm}^{2} \mathrm{~V}^{-1} \mathrm{~s}^{-1}$ in $\mathrm{ZnO}$ nano-particle film and $>100 \mathrm{~cm}^{2} \mathrm{~V}^{-1} \mathrm{~s}^{-1}$ in bulk $\mathrm{ZnO}$ ). Recently, significant efforts have been given to the $\mathrm{ZnO}$ photoanode in place of the porous $\mathrm{TiO}_{2}$ photoanode, in the hope of further enhancing the performance of solar cells by improving electron gathering and transporting efficiency and inhibiting charge recombination at the same time [36]. However, the instability of $\mathrm{ZnO}$ in acid dyes and its low electron injection efficiency from Ru-based dyes resulted in a low conversion efficiency of DSSC based on a pure $\mathrm{ZnO}$ photoanode [7]. Therefore, photoanodes built by two or more materials have attracted new attention due to the obvious advantages of combining different materials, that is, the high electron transport rate of $\mathrm{ZnO}$ and the high electron injection efficiency of $\mathrm{TiO}_{2}$ from Ru-based dyes.

In this paper, a hybrid photoanode composed of $\mathrm{ZnO}$ and $\mathrm{TiO}_{2}$ was fabricated on a $\mathrm{SnO}_{2}$ : F (FTO) transparent conductive glass substrate using different techniques including electrophoretic deposition, screen printing, and colloidal spray coating. Two kinds of $\mathrm{ZnO}$, namely, $\mathrm{ZnO}$ tetrapods and $\mathrm{ZnO}$ nanorods, were adopted in this study. The structural and morphological characterizations of the composite thin films were carried out using scanning electron microscope (SEM). The current density-voltage (I-V) curve, under AM 1.5 illumination with a $100 \mathrm{~mW} / \mathrm{cm}^{2}$ light intensity, was measured and analyzed.

\section{Experimental}

2.1. ZnO Tetrapods and Nanorods Synthesis. ZnO tetrapods were prepared via the thermal evaporation method from our previous report [8]. ZnO nanorods were synthesized on the FTO glass substrates, with predeposited $\mathrm{ZnO}$ seed particles via the hydrothermal growth route. The $\mathrm{ZnO}$ seed layer was 
prepared through combining a sol-gel process and a spincoating technique, following the steps reported in [9].

2.2. Screen Printing. Approximately, $2.0 \mathrm{~g}$ of $\mathrm{TiO}_{2}$ and $2.0 \mathrm{~g}$ of $\mathrm{ZnO}$ tetrapods were dispersed into two mixtures, each containing $0.4 \mathrm{~g}$ PEG-20000, $10 \mathrm{~mL}$ terpineol, $0.4 \mathrm{~g}$ ethyl cellulose, and $0.4 \mathrm{~mL}$ acetylacetone, and ground for $2 \mathrm{~h}$, respectively.

A $\mathrm{TiO}_{2}$ layer was screen printed on the faced-up conductive surface and then annealed at $450^{\circ} \mathrm{C}$ for $0.5 \mathrm{~h}$. The procedure was repeated for the $\mathrm{ZnO}$ mixture. Lastly, another $\mathrm{TiO}_{2}$ layer was screen printed and annealed under the same conditions. An alternative method for this process would be to spin coat one layer of $\mathrm{TiO}_{2}$ sol first, and then screen printing the $\mathrm{ZnO} / \mathrm{TiO}_{2}$ layers to get the composite thin films.

2.3. Colloidal Spray Coating. The slurry used in colloidal spray coating is same with that used in screen printing. FTO glasses were vertically fixed on the walls with paper tape, and the spray gun is $30 \mathrm{~cm}$ away from the glasses. A $\mathrm{ZnO}$ layer was first spray coated on the FTO glasses followed by another $\mathrm{TiO}_{2}$ layer. Afterward, the composite $\mathrm{ZnO} / \mathrm{TiO}_{2}$ layers were annealed at $450^{\circ} \mathrm{C}$ for $0.5 \mathrm{~h}$.

2.4. Electrophoretic Deposition. The preparation of $\mathrm{ZnO}$ tetrapods $/ \mathrm{TiO}_{2}$ thin films through electrophoresis involves the following steps: (1) the mixture of $0.1000 \mathrm{~g} \mathrm{ZnO}$ tetrapods and $0.0010 \mathrm{~g} \mathrm{TiO}_{2}$ were dispersed into the mixed solvent composed of $75 \mathrm{~mL}$ of ethanol and $25 \mathrm{~mL}$ of water under ultrasonic dispersion for $10 \mathrm{~min}$; (2) two clean FTO glass substrates were used as positive and negative electrodes with a $1.5 \mathrm{~cm}$ space between the two electrode surfaces; (3) the electrophoresis voltage was set to $60 \mathrm{~V}$; (4) the sample was annealed at $150^{\circ} \mathrm{C}$ for $20 \mathrm{~min}$ after electrophoresis; (5) steps $1-4$ were repeated to obtain three $\mathrm{ZnO}$ tetrapods $/ \mathrm{TiO}_{2}$ layers; (6) finally, the composite films were annealed at $450^{\circ} \mathrm{C}$ for $0.5 \mathrm{~h}$.

2.5. $\mathrm{ZnO}$ Nanorods $/ \mathrm{TiO}_{2}$ Composite Film. $\mathrm{TiO}_{2}$ sol was first prepared using $16 \mathrm{~mL}$ of tetrabutyltitanate, $10 \mathrm{~mL}$ of ethylene glycol monomethylether, $40 \mathrm{~mL}$ of ethanol, and $0.0240 \mathrm{~g}$ of PEG, which were mixed and stirred at $60^{\circ} \mathrm{C}$.

Subsequently, the FTO glass with $\mathrm{ZnO}$ nanorods was soaked in the solution for about $0.5 \mathrm{~h}$ and then annealed at $450^{\circ} \mathrm{C}$ for $0.5 \mathrm{~h}$.

2.6. DSSC Assembly. The prepared $\mathrm{ZnO} / \mathrm{TiO}_{2}$ hybrid photoanodes were immersed in a N3 ethanol solution for $5 \mathrm{~h}$ to absorb the dye and then washed with ethanol several times. A Pt-coated FTO glass was used as a counterelectrode. The electrolyte was then dropped into it, and a sandwich type of solar cell was fabricated and employed to measure the phototo-electric conversion efficiency.

2.7. Characterizations. The morphology of the $\mathrm{ZnO} / \mathrm{TiO}_{2}$ composite photoanodes was measured using SEM (Hitachi S-4800). The $I-V$ characteristics of the solar cells were

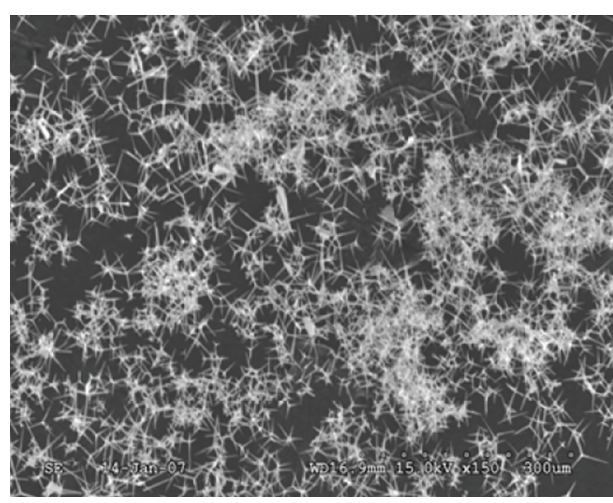

Figure 1: SEM image of the $\mathrm{ZnO}$ tetrapods.

measured using a Keithley 2410 source meter under 1-sun illumination (AM 1.5, $100 \mathrm{~mW} / \mathrm{cm}^{2}$ ) from a solar simulator.

\section{Results and Discussion}

3.1. Morphology of $\mathrm{ZnO}$ and $\mathrm{ZnO} / \mathrm{TiO}_{2}$ Composite Film. Figure 1 shows the SEM image of the $\mathrm{ZnO}$ tetrapods obtained via the thermal evaporation method, which is the easiest way to prepare $\mathrm{ZnO}$ tetrapods. Zinc powder was placed directly into the reactor for thermal evaporation and oxidation. No catalyst is needed in this process, and the reaction atmosphere needs not be controlled in the reactor as well. In addition, the $\mathrm{ZnO}$ tetrapods prepared using thermal evaporation exhibited perfect morphology with high crystal quality.

Figure 2 shows the SEM image of $\mathrm{ZnO}$ nanorods obtained via hydrothermal growth. The $\mathrm{ZnO}$ nanorods showed perfect hexagonal shapes with good orientations.

Figure 3 shows the cross-sectional and top-view images of the $\mathrm{ZnO}$ tetrapods/ $/ \mathrm{TiO}_{2}$ photo-anode fabricated via screen printing. The image shows that the $\mathrm{ZnO}$ tetrapods/ $\mathrm{TiO}_{2}$ composite film exhibits a uniform porous structure, which can greatly increase the surface area and improve dye absorption.

Figure 4 shows the SEM image of the composite film fabricated through colloidal spray coating. The film also has a porous structure. However, this porous structure is not uniform compared with the film prepared via screen printing. Figure 5 presents the morphology of the electrophoretic deposited $\mathrm{ZnO}$ tetrapods/ $/ \mathrm{TiO}_{2}$ composite film, which also shows a porous structure.

Figure 6 shows the morphology of $\mathrm{ZnO}$ nanorods $/ \mathrm{TiO}_{2}$ composite film, and the $\mathrm{TiO}_{2}$ nanoparticles show a dense packing that is unfavorable to dye absorption.

3.2. DSSC Performance. Figure 7 shows the $I-V$ characteristics of DSSC under AM 1.5 illumination with a $100 \mathrm{~mW} / \mathrm{cm}^{2}$ light density. The short-circuit current density (JSC), opencircuit voltage (VOC), fill factor (FF), and energy conversion $(\eta)$ derived from the $I-V$ curve are listed in Table 1 . The DSSC based on the screen printing laminated $\mathrm{TiO}_{2} / \mathrm{ZnO}$ tetrapods $/ \mathrm{TiO}_{2}$ photoanode has the highest efficiency of 


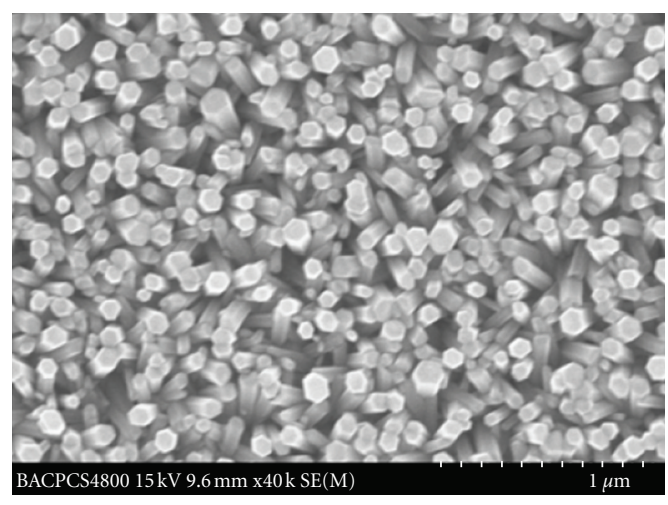

Figure 2: SEM top-view image of the $\mathrm{ZnO}$ nanorods.

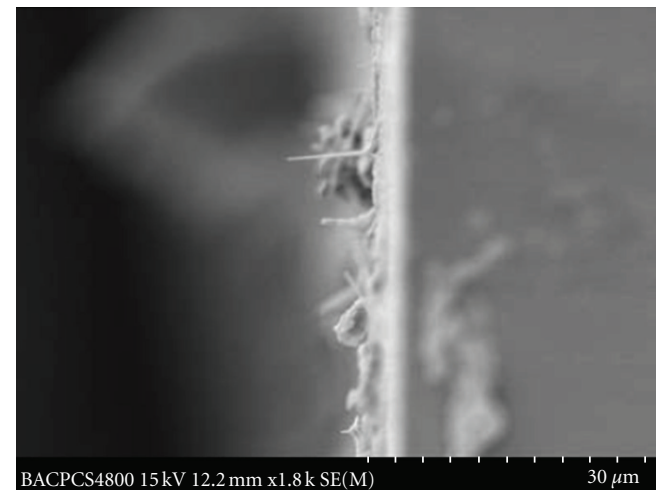

(a)

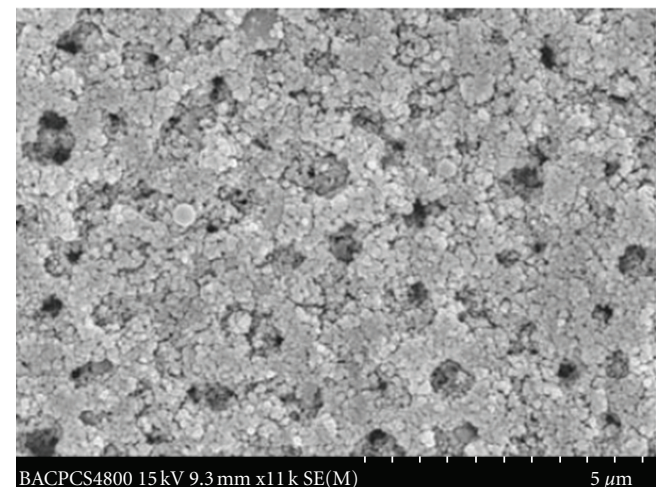

(b)

Figure 3: SEM cross-sectional (a) and top-view image (b) of $\mathrm{ZnO}$ tetrapods $/ \mathrm{TiO}_{2}$ photoanode fabricated via screen printing.

$1.87 \%$, which is attributed to its uniform porous structure. On the other hand, the colloidal spray coated $\mathrm{ZnO}$ tetrapods $/ \mathrm{TiO}_{2}$ composite film has a nonuniform porous structure; thus, the efficiency of DSSC based on it decreased to $0.34 \%$. The $\mathrm{ZnO}$ nanorod/ $/ \mathrm{TiO}_{2}$ has a densely packed structure and is unfavorable for dye absorption, causing its efficiency to decrease to $0.24 \%$. The DSSC based on the electrophoretic deposited $\mathrm{ZnO}$ tetrapods/ $/ \mathrm{TiO}_{2}$ composite photoanode has the lowest efficiency of $0.1 \%$, which may be due to the microlevel size of the $\mathrm{ZnO}$ tetrapods.

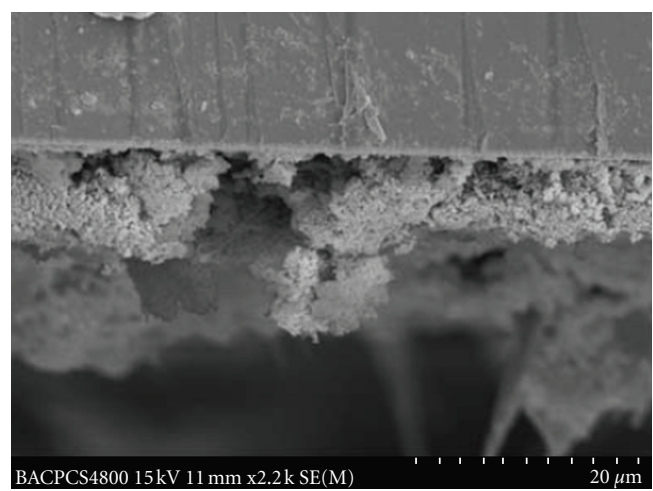

(a)

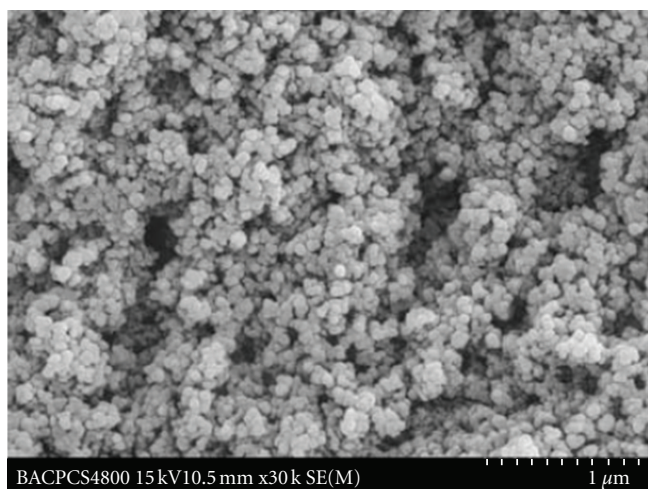

(b)

FIGURE 4: SEM cross-sectional (a) and top-view image (b) of $\mathrm{ZnO}$ tetrapods $/ \mathrm{TiO}_{2}$ photoanode fabricated through colloidal spray coating.

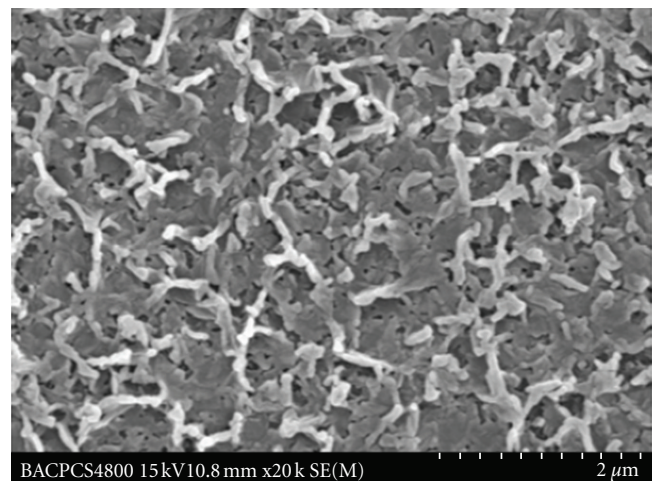

FIGURE 5: SEM image of $\mathrm{ZnO}$ tetrapods/ $/ \mathrm{TiO}_{2}$ photoanode fabricated via electrophoretic deposition.

This condition is unfavorable to electrophoretic deposition, resulting in a poor quality composite film. Another reason may be that the best ratio of $\mathrm{ZnO}$ to $\mathrm{TiO}_{2}$ and the optimal electrophoresis parameters remain unknown. On account of the high electron transport efficiency and a variety of morphology structures of $\mathrm{ZnO}, \mathrm{ZnO} / \mathrm{TiO}_{2}$ composite photoanodes still prove to be very good prospects in improving the photoelectric conversion efficiency of DSSCs. 


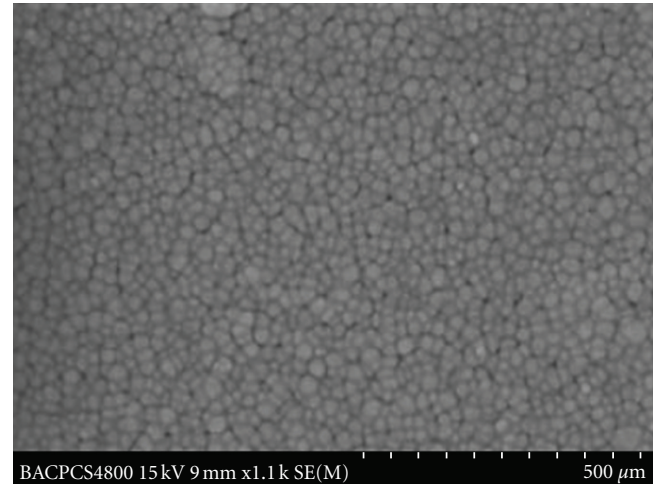

FIgURe 6: SEM image of $\mathrm{ZnO}$ nanorods/ $/ \mathrm{TiO}_{2}$ photoanode.

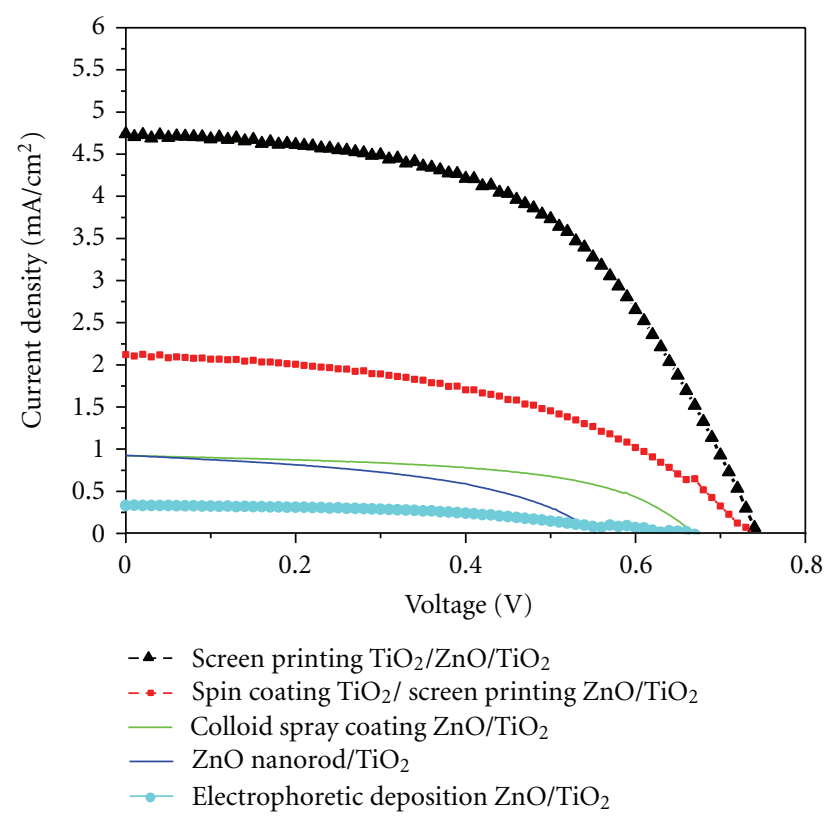

Figure 7: IV curve of DSSC based on $\mathrm{ZnO} / \mathrm{TiO}_{2}$ composite film.

\section{Conclusions}

Hybrid $\mathrm{ZnO} / \mathrm{TiO}_{2}$ photoanodes were prepared using electrophoresis deposition, screen printing, and colloidal spray coating to utilize the high electron transport rate of $\mathrm{ZnO}$ and the high electron injection efficiency and stability of $\mathrm{TiO}_{2}$ materials. DSSCs based on these hybrid photoanodes were assembled. DSSC based on screen printing has the highest power conversion of $1.87 \%$, whereas DSSC based on electrophoresis deposition has the lowest power conversion of $0.10 \%$. Meanwhile, the large-sized $\mathrm{ZnO}$ tetrapods from thermal evaporation are not suitable for electrophoresis deposition and yielded a poor quality electrophoresis film. Thus, smaller-sized $\mathrm{ZnO}$ tetrapods from microemulsion and organic pyrolysis methods will be used for future electrophoresis deposition processes.
TABLE 1: Photovoltaic performance of DSSC based on $\mathrm{ZnO} / \mathrm{TiO}_{2}$ composite film.

\begin{tabular}{lcccc}
\hline Samples & Jsc $\left(\mathrm{mA} / \mathrm{cm}^{2}\right)$ & Voc $(\mathrm{V})$ & FF & Eff $(\%)$ \\
\hline 1 & 4.74 & 0.74 & 0.53 & 1.87 \\
2 & 2.12 & 0.74 & 0.47 & 0.73 \\
3 & 0.92 & 0.67 & 0.55 & 0.34 \\
4 & 0.93 & 0.55 & 0.46 & 0.24 \\
5 & 0.34 & 0.67 & 0.43 & 0.10 \\
\hline
\end{tabular}

\section{Acknowledgments}

The work was supported by National Natural Science Foundation of China (60907014) and School Foundation of Beijing Jiaotong University (2009JBZ019-2), (2009JBM110).

\section{References}

[1] B. O'regan and M. Grätzel, "A low-cost, high-efficiency solar cell based on dye-sensitized colloidal $\mathrm{TiO}_{2}$ films," Nature, vol. 353, no. 6346, pp. 737-740, 1991.

[2] M. Grätzel, "Conversion of sunlight to electric power by nanocrystalline dye-sensitized solar cells," Journal of Photochemistry and Photobiology A, vol. 164, no. 1-3, pp. 3-14, 2004.

[3] M. Law, L. E. Greene, J. C. Johnson, R. Saykally, and P. D. Yang, "Nanowire dye-sensitized solar cells," Nature Materials, vol. 4, no. 6, pp. 455-459, 2005.

[4] A. B. F. Martinson, J. W. Elam, J. T. Hupp, and M. J. Pellin, " $\mathrm{ZnO}$ nanotube based dye-sensitized solar cells," Nano Letters, vol. 7, no. 8, pp. 2183-2187, 2007.

[5] L. E. Greene, B. D. Yuhas, M. Law, D. Zitoun, and P. D. Yang, "Solution-grown zinc oxide nanowires," Inorganic Chemistry, vol. 45, no. 19, pp. 7535-7543, 2006.

[6] W. Chen, H. Zhang, I. M. Hsing, and S. Yang, "A new photoanode architecture of dye sensitized solar cell based on $\mathrm{ZnO}$ nanotetrapods with no need for calcination," Electrochemistry Communications, vol. 11, no. 5, pp. 1057-1060, 2009.

[7] Q. Zhang, C. S. Dandeneau, X. Zhou, and C. Cao, "ZnO nanostructures for dye-sensitized solar cells," Advanced Materials, vol. 21, no. 41, pp. 4087-4108, 2009.

[8] W. Peng, Y. Luting, W. Hongpeng, Z. Chunyan, and S. Wenjie, "Effect of process parameters on the preparation T-ZnOw," Journal of Materials Science \& Engineering, vol. 27, no. 1, pp. 75-77, 2009.

[9] M. Ohyama, H. Kozuka, and T. Yoko, "Sol-gel preparation of $\mathrm{ZnO}$ films with extremely preferred orientation along (002) plane from zinc acetate solution," Thin Solid Films, vol. 306, no. 1, pp. 78-85, 1997. 


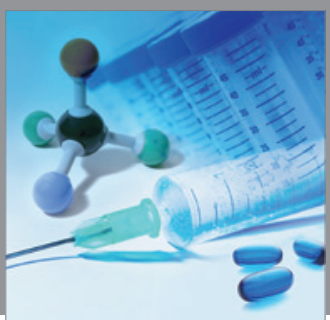

International Journal of

Medicinal Chemistry

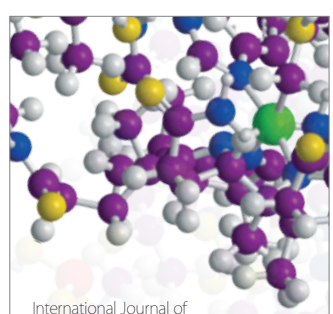

Carbohydrate Chemistry

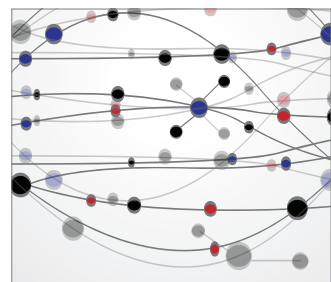

The Scientific World Journal
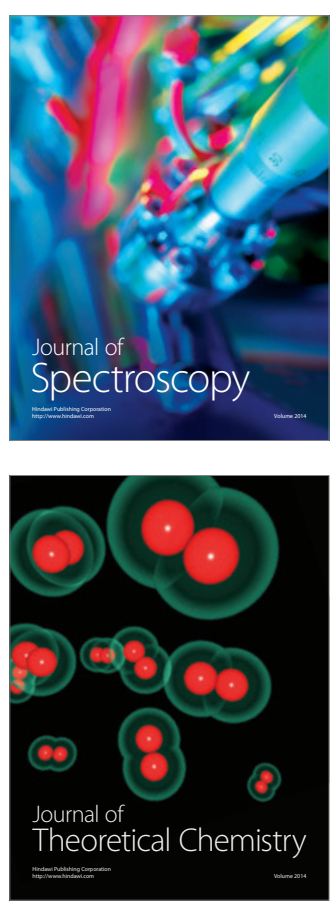
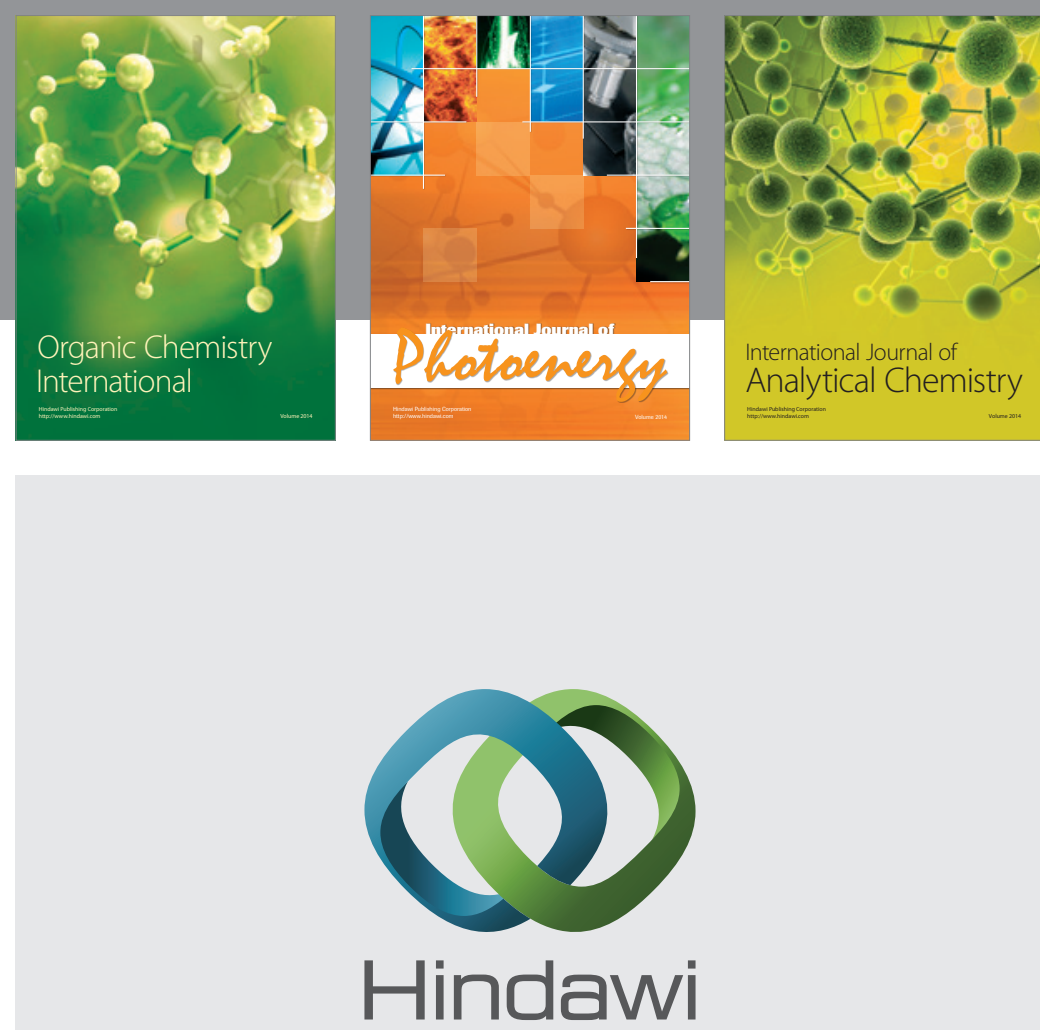

Submit your manuscripts at

http://www.hindawi.com
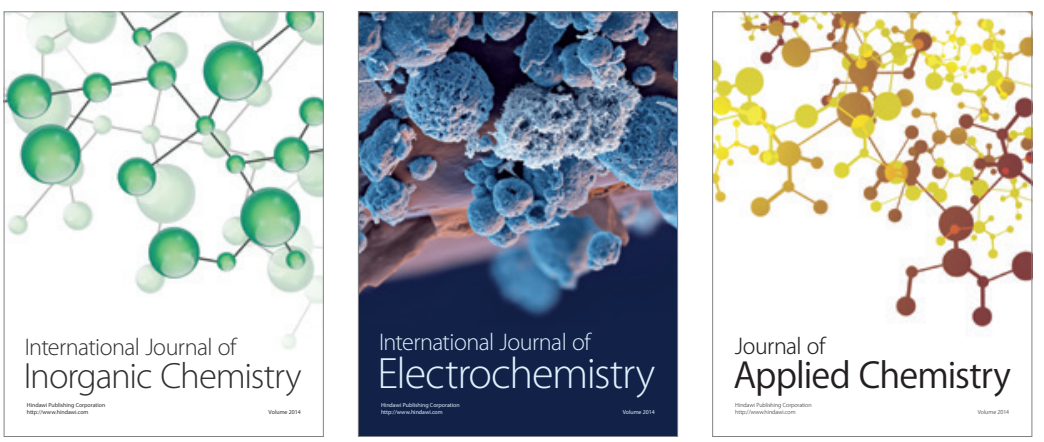

Journal of

Applied Chemistry
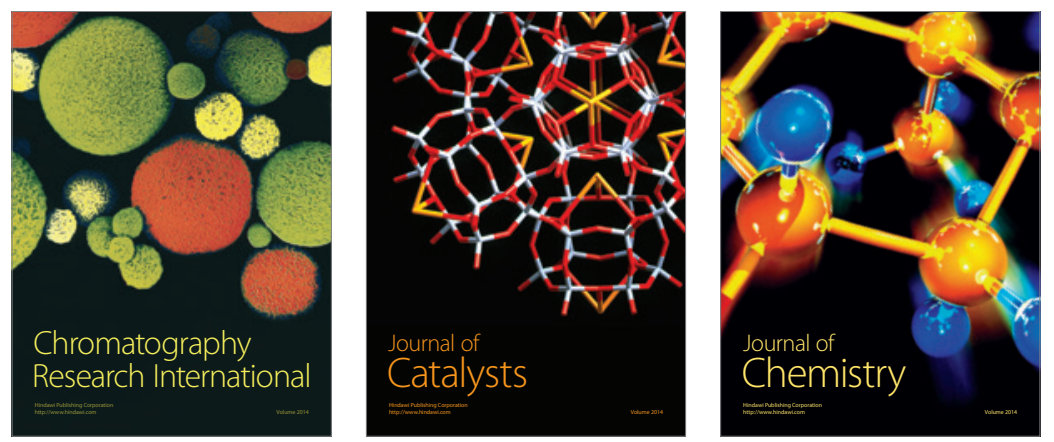
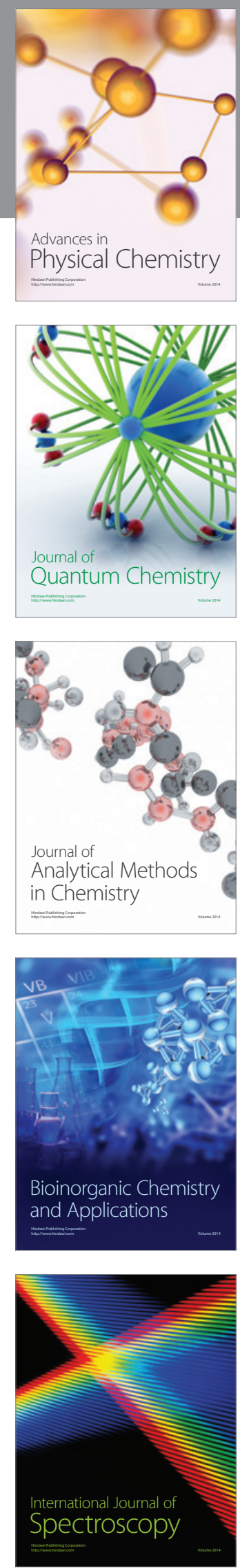